\title{
Pengaruh Brand Image Terhadap Keputusan Menggunakan Jasa Klinik Kecantikan Dengan Kelompok Referensi Sebagai Variabel Moderasi (Studi Pada Pengguna Jasa Klinik Kecantikan Di Surabaya)
}

\author{
Ana Fitria ${ }^{1}$, Sri Setyo Iriani $^{2}$ 'Sanaji ${ }^{3}$ \\ 1 Alumni Fakultas Ekonomi Universitas Negeri Surabaya \\ 2,3, Dosen Fakultas Ekonomi Universitas Negeri Surabaya \\ annaanfit69@gmail.com ${ }^{1}$, srisetyo@unesa.ac.id ${ }^{2}$, dataaji03@gmail.com ${ }^{3}$
}

\begin{abstract}
Consumer perceptions of brands are based on experience and information obtained by consumers. Consumers seek information to evaluate brands before deciding to use the brand. Friends are one of the most effective sources of information in influencing consumer purchasing decisions. This study aims to analyze and discuss the influence of brand image on purchase decision of beauty clinic services that moderated by reference group. This reseach used 220 sample from four beauty clinic services in Surabaya and applied moderating regression analysis to test the research model. The results showed that brand image had a positive and significant influence on the decision to use the beauty clinic services, while reference group con not moderating the influence brand image on the decision to use the beauty clinic services.
\end{abstract}

Keywords : brand image, reference group, use decision

\section{Pendahuluan}

Saat ini banyak wanita yang mulai sadar terhadap penampilan. Tidak hanya pada pakaian saja, namun kecantikan wajah juga merupakan prioritas utama dalam penampilan wanita. Selain menggunakan kosmetik, untuk menunjang kecantikan wajah para wanita juga melakukan perawatan, baik dilakukan sendiri secara sederhana hingga menggunakan jasa klinik kecantikan. Hal ini mendorong semakin meningkatnya jumlah jasa klinik kecantikan. Masing-masing jasa klinik kecantikan berusaha untuk menciptakan citra merek positif dalam benak konsumen. Citra merek termasuk hal penting yang dipertimbangkan konsumen dalam keputusan pembelian, karena brand image atau brand description merupakan deskripsi tentang asosiasi dan keyakinan konsumen terhadap merek yang menjadi pegangan konsumen dalam pengambilan keputusan (Tjiptono, 2011 : 112). Hal yang sama juga diungkapkan oleh Suryati (2012 : 113), bahwa citra merek mempunyai peran penting dalam mempengaruhi perilaku pembelian. Ketika konsumen mempunyai citra positif terhadap suatu merek maka ia cenderung memilih merek tersebut dalam pembelian. Sesuai dengan penelitian yang dilakukan Rakhmat (2013) dan Shahbazi, dkk (2013), brand image dapat berpengaruh positif terhadap keputusan memilih layanan kesehatan dan salon kecantikan. Dan juga penelitian dari Lin dan Lin (2007), brand image dapat mempengaruhi keputusan pembelian pada kosmetik dan produk perawatan kulit.

Klinik kecantikan termasuk jasa yang mempunyai tingkat keterlibatan tinggi dengan konsumen. Untuk pembelian dengan keterlibatan tinggi, para pemasar harus menggunakan pendapat yang memiliki sifat-sifat yang kuat, kokoh serta berkualitas tinggi pada produk mereka agar meyakinkan konsumen (Sciffman dan Kanuk, 2008 : 207). Untuk mengurangi 
Sanaji

resiko pembelian, cara yang dilakukan konsumen adalah mencari informasi melalui teman, kerabat atau sumber informasi lain yang akan digunakan referensi sebelum mengambil keputusan (Suryani 2012: $114-116$ ).

Suatu kelompok dapat berpengaruh kuat dalam hal pemilihan merek ketika kelompok itu memiliki informasi yang lengkap dan banyak tentang berbagai merek, sehingga akan terjadi pengaruh berupa perubahan pendapat, perubahan sikap, dan perubahan perilaku (Suryani 2012 : 224-226). Hal yang sama juga diungkapkan oleh Kotler dan Keller (2009 : 189), bahwa konsumen akan menyesuaikan niat pembeliannya dengan orang memiliki hubungan dekat dengannya dan orang tersebut mempunyai persepsi yang negatif terhadap suatu merek. Dibuktikan dalam penelitian yang dilakukan oleh Kim dan Qu (2016), bahwa citra tempat wisata berpengaruh terhadap sikap persepsi dan perilaku wisatawan dalam menilai tempat wisata di Asia yang dimoderasi oleh kelompok referensi. Dan juga penelitian dari Escalas dan Bettman (2003), bahwa anggota kelompok lebih menyukai merek yang dikenal oleh kelompok aspirasi.

Sebelum memutuskan pembelian, konsumen akan mengumpulkan berbagai informasi yang dibutuhkan mengenai produk. Sumber informasi yang sering digunakan adalah sumber pribadi, seperti keluarga, teman, tetangga, dan rekan (Kotler dan Keller 2009 : 185). Pendapat atau kesukaan teman mampu berpengaruh dalam pengambilan keputusan konsumen ketika membeli dan memilih produk dan juga merek (Sumarwan 2011 : 308). Dapat dibuktikan dengan penelitian yang dilakukan oleh Hoonsopon and Puriwat (2016), bahwa kelompok referensi yang berasal dari keluarga dan teman memiliki pengaruh yang lebih besar pada niat beli produk yang memiliki tingkat keterlibatan yang tinggi. Hal yang sama juga diungkapkan oleh Pramudi (2015) dan Akbarini (2017).

Dari semua jasa klinik kecantikan yang ada di Indonesia, menurut Top Brand Index tahun 2017 terdapat lima merek klinik kecantikan, yaitu Natasha Skin Care, Erha Clinic, London Beauty Center, Miracle Skin Care, Klinik Dr. Eva Mulia. Dari ke lima klinik kecantikan, satu yang tidak terdapat di Surabaya yaitu Dr. Eva Mulia. Sedangkan lainnya banyak tersebar di Surabaya dengan beberapa cabang. Disini diasumsikan jumlah cabang dapat mengindikasikan jumlah pelanggan.

\section{Tabel 1}

Top Brand Index Tahun 2015-2017 Klinik Kecantikan dan Jumlah Cabang di Surabaya

\begin{tabular}{|lcccc|}
\hline \multicolumn{1}{|c}{ Merek } & $\mathbf{2 0 1 5}$ & $\mathbf{2 0 1 6}$ & $\mathbf{2 0 1 7}$ & $\begin{array}{c}\text { Jumlah } \\
\text { Cabang }\end{array}$ \\
\hline Natasha Skin Care & $34,9 \%$ & $40,1 \%$ & $38.2 \%$ & 4 \\
Erha Clinic & $17,1 \%$ & $17,4 \%$ & $17.4 \%$ & 5 \\
London Beauty Center & $5,10 \%$ & $6,4 \%$ & $6.0 \%$ & 2 \\
Miracle Skin Care & $2,5 \%$ & $2,9 \%$ & $2.4 \%$ & 4 \\
\hline
\end{tabular}

Sumber : www.topbrand-award.com dan website perusahaan terkait, 2017

Dari tabel di atas dapat disimpulkan bahwa Erha Clinic memiliki jumlah pelanggan terbanyak karena memiliki cabang paling banyak yaitu 5 cabang, selanjutnya Natasha Skin Care dan Miracle Aesthetic Center dengan 4 cabang dan yang paling sedikit adalah London Beauty Center dengan 2 cabang. Selain memperbaiki citra merek, jasa klinik kecantikan juga melakukan perbaikan dalam pelayanan. Ketika konsumen mendapatkan kualitas pelayanan bagus maka konsumen dapat merasakan kepuasan yang tinggi (Tjiptono dan Chandra 2012 :76). Pelanggan akan memberi penilaian yang sangat subjektif terhadap jasa yang diberikan karena mereka dapat merasakan langsung kualitas pelayanan (Lupiyoadi 2014 : 197). Dalam 
Sanaji

penelitian Kitapchi, dkk (2014), menyatakan bahwa kepuasan terhadap kualitas pelayanan dapat memediasi pengaruh word of mout terhdap keputusan menggunakan klinik kesehatan, sehingga ketika konsumen puas terhadap pelayanan yang diberikan, konsumen cenderung merekomendasikannya kepada orang lain agar menggunakan produk yang sama dengannya.

\section{Landasan Teori Dan Pengembangan Hipotesis}

\section{Brand Image}

Faktor yang menjadi bahan pertimbangan konsumen sebelum memutuskan pembelian salah satunya adalah brand image. Seperti apa konsumen mempersepsikan suatu merek dalam ingatannya Brand image merupakan persepsi konsumen terhadap suatu merek dan seperti apa konsumen memberikan refleksi pada merek tersebut (Keller 1993) dalam Ferrinadewi 2008 : 165). Sedangkan Tjiptono (2011 : 112), berpendapat brand image atau brand description merupakan cara konsumen mendeskripsikan asosiasi dan keyakinan konsumen terhadap merek tertentu. Keller (2013 :72), mendeskripsikan brand image adalah persepsi konsumen terhadap suatu merek, seperti yang dicerminkan dalam asosiasi yang tertanam di ingatan konsumen. Dari beberapa pengertian diatas dapat disimpulkan bahwa brand image adalah pandangan konsumen terhadap suatu merek yang didasarkan atas pengetahuan konsumen terhadap suatu merek tersebut. Sehingga bagaimana nilai dari suatu merek tersebut dipersepsikan oleh konsumen.

Menurut Keller (2013 : 78 - 79) terdapat tiga faktor yang dapat membentuk citra merek yang dievaluasi oleh konsumen yakni Strenght of brand associaton (kekuatan asosiasi merek), Uniqueness of brand association (keunikan asosiasi merek) dan Favorability of brand associaton (keuntungan asosiasi merek). Dalam penelitian ini indikator yang digunakan merujuk pada penelitian Mahmudah dan Tiarawati (2013) yaitu, keuntungan dari asosiasi merek, kekuatan dari asosiasi merek dan keunikan dari asosiasi merek yang diukur menggunakan pra penelitian pada keempat jasa klinik kecantikan.

\section{Kelompok Referensi}

Kelompok referensi merupakan kelompok yang digunakan sebagai alasan pembandingan atau acuan dalam membentuk respons afektif, kognitif dan perilaku yang melibatkan satu orang atau lebih (Peter dan Olson 2014 : 132). Sedangkan menurut Kotler dan Keller (2009 : 170), kelompok referensi adalah semua kelompok yang mempunyai pengaruh langsung (tatap muka) atau tidak langsung terhadap sikap atau perilaku seseorang tersebut. Menurut Sumarwan (2011 : 305), kelompok referensi adalah seorang individu atau sekelompok orang yang secara nyata mempengaruhi perilaku seseorang. Kelompok referensi digunakan oleh seseorang sebagai dasar untuk perbandingan atau sebuah referensi dalam membentuk respon afektif, kognitif dan perilaku.

Kelompok referensi dapat mempengaruhi keputusan pembelian konsumen melalui tiga cara dasar yaitu pengaruh normatif, pengaruh nilai, dan pengaruh informasi (Sumarwan 2011 : 308). Menurut Sumarwan (2011 : 308) macam-macam kelompok referensi yang terkait dengan konsumen, yaitu Kelompok persahabatan (Friendship Groups), Kelompok belanja (Shopping Groups), Kelompok kerja (Work Groups), Kelompok Pegiat Konsumen (Consumer Action Groups) dan Masyarakat atau kelompok maya (Virtual Groups or Communities).

Dalam penelitian ini jenis kelompok referensi yang digunakan adalah kelompok referensi informal, yaitu kelompok yang keanggotaannya tidak tercatat serta tidak terdapat 
Sanaji

struktur organisasi secara resmi dan tertulis dengan bentuk pengaruh normatif seperti kelompok teman. Indikator yang digunakan untuk mengukur pengaruh kelompok referensi merujuk pada penelitian Kim dan Qu (2016), yaitu information reference group influence, value-espressive reference group influence dan utilitarian reference group influence.

\section{Keputusan Pembelian}

Keputusan adalah proses untuk memilih satu dari dua pilihan alternatif atau lebih (Schiffman dan Kanuk 2008 : 485). Sedangkan menurut Peter-Olson dalam Nitisusastro (2012 : 195), pengambilan keputusan konsumen adalah proses interaksi antara sikap afektif, kognitif dan behavioral terhadap faktor lingkungan dimana manusia saling bertukar dalam berbagai aspek kehidupan. Sehinga disimpulkan keputusan dalam pembelian merupakan suatu langkah atau perilaku yang dilakukan seseorang untuk suatu keputusan dari beberapa alternatif. Sehingga sebelumnya telah melewati beberapa tahap sebelum akhirnya konsumen memilih produk atau jasa yang dipersepsikan mampu memenuhi kebutuhannya. Dalam penelitian ini, indikator keputusan pembelian mengacu pada teori Kotler dan Keller 2009 : 178) dan Pramudi (2015) dan disesuaikan dengan objek penelitian jasa klinik kecantikan yaitu pilihan merek, jumlah pembelian dan waktu pembelian.

\section{Hubungan Brand Image dan Keputusan Menggunakan Jasa Klinik Kecantikan}

Suryati (2012 : 113), perilaku pembelian konsumen dipengaruhi oleh peran penting dari citra yang dipersepsikan seseorang terhadap suatu merek. Ketika konsumen mempunyai citra yang baik terhadap suatu merek maka konsumen cenderung memilih merek tersebut dalam pembeliannya. Sutisna (2001 : 83) dalam Mahmudah (2013), menyatakan bahwa konsumen lebih memungkinkan untuk melakukan pembelian ketika konsumen tersebut memiliki citra merek yang positif terhadap suatu merek. Menurut Sumarwan (2011 : 169), konsumen yang mempunyai pengetahuan yang baik mengenai suatu produk dapat mendorong seseorang untuk menyukai produk tersebut. Sehingga ketika konsumen sudah mengenal atau menyukai merek, konsumen kemudian akan membeli produk tersebut.

Teori tersebut diatas sesuai dalam penelitian yang dari Rakhmat (2013) dan Shahbazi, dkk (2013) yang mana brand image berpengaruh positif terhadap keputusan menggunakan layanan kesehatan dan salon kecantikan. Serta penelitian Lin dan Lin (2007) bahwa brand image dapat mempengaruhi keputusan pembelian pada kosmetik dan produk perawatan kulit. Berdasarkan uraian tersebut di atas dapat diperoleh hipotesis penelitian, yaitu :

H1 : Brand Image memiliki pengaruh terhadap keputusan menggunakan jasa klinik kecantikan.

\section{Hubungan Brand Image dan Keputusan Menggunakan Jasa Klinik Kecantikan Dengan Kelompok Referensi Sebagai Variabel Moderasi}

Suatu kelompok mempunyai pengaruh kuat dalam pemilihan merek ketika kelompok tersebut mempunyai banyak informasi dan lengkap dalam berbagai merek (Suryani 2012 : 226). Kelompok juga mempengaruhi perilaku seseorang melalui komunikasi dan informasi yang mereka sebarkan, sehingga terjadi pengaruh berupa perubahan pendapat, perubahan sikap, dan perubahan perilaku (Suryani 2012 : 224). Menurut Kotler dan Keller (2009 : 189), ketika konsumen menilai suatu merek, sikap orang lain dapat mempengaruhinya. Konsumen 
Sanaji

akan menyesuaikan niat pembeliannya dengan orang yang memiliki hubungan dekat dengannya dan orang tersebut memiliki persepsi negatif terhadap suatu merek.

Dalam penelitian Kim dan Qu (2016), mengungkapkan bahwa citra tempat wisata berpengaruh terhadap sikap persepsi dan perilaku wisatawan dalam menilai tempat wisata di Asia yang dimoderasi oleh kelompok referensi. Dan penelitian Escalas dan Bettman (2003), menyatakan anggota kelompok lebih menyukai merek yang dikenal oleh kelompok aspirasi dan jika mereka mempersepsikan baik bagi anggota kelompok. Berdasarkan penjelasan di atas dapat diperoleh hipotesis penelitian, yaitu :

H2 : Kelompok referensi memoderasi pengaruh brand image terhadap keputusan menggunakan jasa klinik kecantikan.

\section{Model Penelitian}

Rancangan penelitian pada penelitian ini adalah konklusif dengan pendekatan deskriptif yang digunakan untuk menjelaskan karakteristik dan fungsi pasar yang ditandai dengan formulasi hipotesis spesifik yang dilakukan sebelumnya.

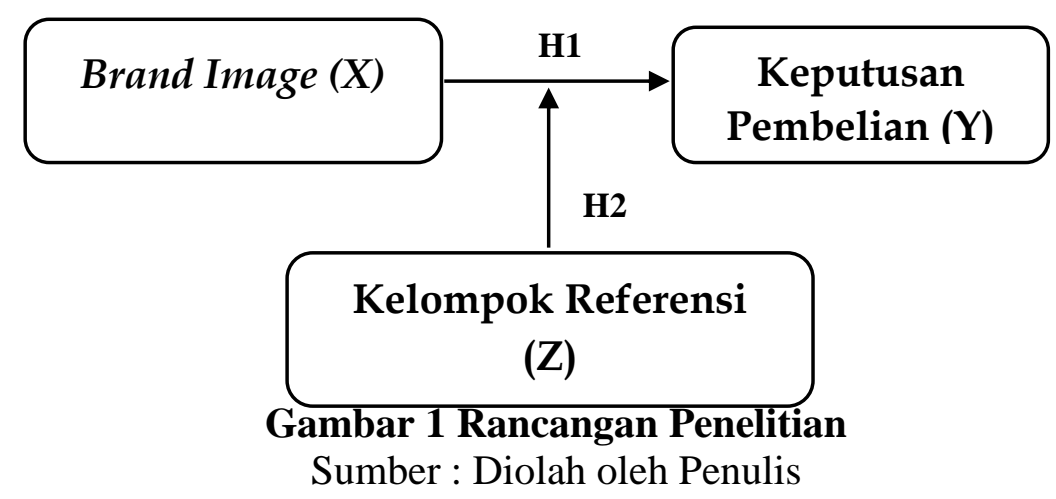

\section{Metode Penelitian}

Lokasi penelitian dalam penelitian ini adalah di klinik dan di luar klinik. Di klinik yaitu klinik kecantikan Natasha Skin Care, Erha Clinic, London Beauty Center, dan Miracle Skin Care yang ada di Surabaya. Sedangkan di luar klinik yaitu ketika terdapat konsumen dari salah satu klinik kecantikan namun tidak sedang berada di klinik kecantikan tersebut.

Populasi yang digunakan di penelitian ini merupakan pelanggan yang pernah memustuskan menggunakan salah satu jasa klinik kecantikan, yaitu Natasha Skin Care, Erha Clinic, London Beauty Center, dan Miracle Skin Care yang ada di Surabaya, yang berumur minimal 18 tahun. Dalam penelitian ini sampel dilakukan menggunakan metode nonprobability sampling dan teknik pengambilan sampel sampling incidental dan snowball sampling. Sampel yang digunakan untuk jenis studi pengujian pasar berjumlah 200 responden. Untuk memperoleh data 200 responden ditambahkan 10\% dari jumlah ukuran sampel yang telah ditentukan. Data 220 responden tersebut dibagi secara proposional yang disesuaikan dengan jumlah pelanggan pada empat jasa klinik kecantikan, yaitu Erha Clinic, Natasha Skin Care, London Beauty Center dan Miracle Aesthetic Clinic.

Sumber dan jenis data yang digunakan yaitu data primer dan data sekunder. Data primer diperoleh dengan menyebarkan angket yang berisi tentang karakteristik demografi responden dan tanggapan responden terhadap variabel brand image, kelompok referensi dan keputusan menggunakan jasa klinik kecantikan. Sedangkan data sekunder diperoleh dari buku 
Sanaji

literatur, jurnal pendukung, dan artikel yang berkaitan dengan variabel brand image, kelompok referensi dan keputusan menggunakan jasa klinik kecantikan di Surabaya.

\section{Hasil Dan Pembahasan}

Teknik analisis data yang digunakan adalah uji nilai selisih mutlak dan MRA (Moderated Regression Analysis). Hasil uji validitas diketahui bahwa seluruh item pernyataan memiliki Corrected Item-Total Correlation ( $\mathrm{r}$ hitung) yang lebih besar dari $\mathrm{r}$ tabel, sehingga dapat disimpulkan bahwa pernyataan pada angket dinyatakan valid. Sedangkan hasil uji reliabilitas diketahui besarnya nilai Cronbach's Alpha untuk pengaruh brand image, kelompok referensi, dan keputusan pembelian lebih besar dari 0,70. sehingga disimpulkan pernyataan angket dapat digunakan sebagai alat ukur dalam penelitian ini.

Sebelum dilakukan uji nilai selisih mutlak dan MRA (Moderated Regression Analysis), terlebih dahulu harus memenuhi uji asumsi klasik. Adapun hasil uji asumsi klasik adalah uji normalitas menggunakan analisis grafik histogram diketahui pembentukan garisnya tidak mengalami kemencengan, dan grafik normal plot menunjukkan titik-titik menyebar disekitar dan mengikuti garis diagonalnya. Pada uji statistik diketahui bahwa nilai signifikansi uji Kolmogorov-Smirnov sebesar 0,200 atau lebih besar dari 0,05.

Pada uji multikolonieritas menunjukkan nilai tolerance pada dua variabel bebas lebih besar dari 0,1 dan nilai VIF dari kedua variabel bebas kurang dari 10, maka dapat simpulkan dalam persamaan regresi tidak terjadi multikolonieritas. Pada uji heteroskedastisitas menunjukkan bahwa nilai signifikansi variabel brand image dan interaksi antara brand image dengan kelompok referensi keduanya mempunyai nilai lebih besar dibanding 0,05. Dan jika dilihat dari scatterplot penyebaran residualnya tidak teratur dan tidak membentuk pola tertentu serta tersebar di atas dan di bawah nol.

Dari hasil deskripsi karakteristik responden, dapat diketahui bahwa keputusan menggunakan jasa klinik kecantikan didominasi oleh responden yang berusia 18-28 tahun yang dengan pekerjaan sebagai karyawan swasta dan mempunyai pendapatan di atas Rp 3.000.000. Pada usia tersebut, konsumen sangat menjaga dan memperhatikan penampilan mereka, menggunakan jasa klinik kecantikan diperlukan tidak hanya untuk keperluan seharihari saja, namun selalu berpenampilan menarik dan rapi juga merupakan tuntutan mereka dalam bekerja sebagai karyawan swasta. Menggunakan jasa klinik kecantikan bukan termasuk kebutuhan pokok yang harus dipenuhi sehingga sebagian besar penggunanya adalah konsumen yang mempunyai penghasilan lebih.

Untuk menggunakan MRA dengan satu variabel predictor (X), maka harus membandingkan tiga persamaan regresi. Berikut ini merupakan hasil ringkasan tiga persamaan output regresi yaitu :

Tabel 2

Perbandingan Tiga Persamaan Regresi

\begin{tabular}{|c|l|c|c|c|c|c|}
\hline Persamaan & \multicolumn{1}{|c|}{ Model } & B & Std. Eror & t & Sig. & Keterangan \\
\hline \multirow{2}{*}{2} & ZScore BI & 0,289 & 0,066 & 4,368 & 0,000 & b1 signifikan \\
\hline \multirow{2}{*}{3} & ZScore BI & 0,215 & 0,051 & 4,203 & 0,000 & b1 signifikan \\
\cline { 2 - 7 } & ZScore KR & 0,631 & 0,051 & 12,301 & 0,000 & b2 signifikan \\
\cline { 2 - 7 } & ZScore BI & 0,223 & 0,052 & 4,245 & 0,000 & b1 signifikan \\
\cline { 2 - 7 } & ZScore KR & 0,639 & 0,053 & 12,063 & 0,000 & b2 signifikan \\
\hline
\end{tabular}


Sanaji

\begin{tabular}{|l|l|l|l|l|l|l|}
\hline & BI x KR & 0,042 & 0,063 & 0,0663 & 0,508 & $\begin{array}{l}\text { b3 tidak } \\
\text { signifikan }\end{array}$ \\
\hline
\end{tabular}

Sumber : Diolah Peneliti (Output Regresi IBM SPSS 23)

Keterangan:

$\mathrm{BI}=$ Brand Image $; \mathrm{KR}=$ Kelompok Referensi

Dengan membandingkan ketiga regresi tersebut, dapat dilihat nilai $\mathrm{t}$ hitung variabel brand image sebesar 4,245 dengan signifikansi sebesar 0,000, variabel kelompok referensi dengan nilai t hitung sebesar 12,063 dengan signifikansi sebesar 0,000 dan variabel moderasi antara brand image dengan kelompok referensi dengan nilai $\mathrm{t}$ hitung 0,035 dengan signifikansi sebesar 0,508, maka dapat diambil kesimpulan bahwa variabel brand image dan kelompok referensi signifikan berpengaruh terhadap variabel keputusan menggunakan jasa klinik kecantikan. Sedangkan variabel moderasi antara brand image dengan kelompok referensi tidak signifikan atau dapat diartikan bahwa variabel kelompok referensi tidak dapat berinteraksi dengan brand image. Atau diperoleh informasi bahwa $\beta 2 \neq 0$ (signifikan) dan $\beta 3$ $=0$ (tidak signifikan). Selanjutnya, untuk menentukan jenis variabel moderasi, dapat diketahui melalui tabel berikut ini :

Tabel 3

Jenis-jenis Variabel Moderator

\begin{tabular}{|c|c|c|}
\hline & $\begin{array}{c}\text { Berhubungan dengan } \\
\text { kriterion dan atau } \\
\text { prediktor /(b2 } \\
\text { signifikan) }\end{array}$ & $\begin{array}{c}\text { Tidak berhubungan } \\
\text { dengan kriterion dan atau } \\
\text { prediktor /(b2 tidak } \\
\text { signifikan) }\end{array}$ \\
\hline $\begin{array}{c}\text { Tidak berinteraksi } \\
\text { dengan prediktor/(b3 } \\
\text { tidak signifikan) }\end{array}$ & $\begin{array}{c}\text { Intervening, Exogen, } \\
\text { Antesedent, Prediktor }\end{array}$ & $\begin{array}{c}\text { Moderator } \\
\text { (Homologizer) }\end{array}$ \\
\hline $\begin{array}{c}\text { Berinteraksi dengan } \\
\text { prediktor/(b3 signifikan) }\end{array}$ & $\begin{array}{c}\text { Moderator (Quasi } \\
\text { Moderator) }\end{array}$ & $\begin{array}{c}\text { Moderator (Pure } \\
\text { Moderator) }\end{array}$ \\
\hline
\end{tabular}

Sumber : Sharma et al (1981) dalam Ghozali (2013 : 214)

Setelah membandingkan ketiga persamaan regresi tersebut di atas dapat disimpulkan bahwa variabel moderator (kelompok referensi) berhubungan dengan variabel kriterion (keputusan menggunakan), tetapi variabel moderator (kelompok referensi) tidak berinteraksi dengan prediktor (brand image). Sehingga dapat diambil kesimpulan bahwa variabel kelompok referensi berada di kuadran 1 yang berarti variabel kelompok referensi tergolong dalam variabel prediktor atau variabel independen.

Berikut hasil uji nilai selisih mutlak dan MRA pada penelitian dapat ditujukkan pada tabel dibawah : 


\section{Tabel 4}

Hasil Perhitungan SPSS Uji Selisih Mutlak

\begin{tabular}{|c|c|c|c|c|c|}
\hline Variabel & $\begin{array}{c}\text { Koefisien } \\
\text { Regresi }\end{array}$ & $\mathbf{t}_{\text {hitung }}$ & Sig. & $\begin{array}{l}\text { Konstans } \\
\text { F }_{\text {hitung }}\end{array}$ & $\begin{array}{l}=23,130 \\
=61,168\end{array}$ \\
\hline $\begin{array}{l}X \\
Z \\
X-Z\end{array}$ & $\begin{array}{l}0,223 \\
0,639 \\
0,042\end{array}$ & $\begin{array}{l}4,245 \\
12,063 \\
0,663\end{array}$ & $\begin{array}{l}0,000 \\
0,000 \\
0,508\end{array}$ & $\begin{array}{l}\mathbf{F}_{\text {sig }} \\
\mathbf{R}^{2} \\
\text { Adj } \mathbf{R}^{2} \\
\mathbf{N}\end{array}$ & $\begin{array}{l}=0,000 \\
=0,459 \\
=0,452 \\
=220\end{array}$ \\
\hline
\end{tabular}

Sumber : Diolah Peneliti (Output Regresi IBM SPSS 23)

Dari tabel diatas dapat diperoleh model persamaan MRA (Moderated Regression Analysis) sebagai berikut :

$$
\mathrm{Y}=\mathbf{2 3 , 1 3 0}+\mathbf{0 , 2 2 3} \mathrm{X}+\mathbf{0 , 6 3 9} \mathrm{Z}+\mathbf{0 , 0 4 2}|\mathrm{X}-\mathrm{Z}|+\mathrm{e}
$$

Keterangan :

$$
\begin{array}{lll}
\mathrm{Y} & = & \text { Variabel Terikat (Keputusan Menggunakan) } \\
\mathrm{X} & = & \text { Variabel Bebas (Brand Image) } \\
\mathrm{Z} & = & \text { Variabel Moderator (Kelompok Referensi) }
\end{array}
$$

Berdasarkan pada model MRA di atas, dapat diketahui nilai konstanta sebesar 23,130 diartikan brand image dan kelompok referensi memberikan kontribusi pada keputusan menggunakan jasa klinik kecantikan adalah sebesar 23,130. Makna tanda positif pada koefisien regresi adalah hubungan yang searah, keputusan menggunakan jasa klinik kecantikan akan tinggi ketika konsumen merasakan brand image dan kelompok referensi.

Nilai koefisien brand image adalah 0,223 diartikan jika brand image berubah satu satuan, maka keputusan menggunakan jasa klinik kecantikan akan berubah 0,223 satuan dengan anggapan variabel lain tetap. Tanda positif pada koefisien regresi menunjukkan hubungan yang searah. Semakin baik brand image akan menyebabkan keputusan menggunakan jasa klinik kecantikan semakin tinggi.

Nilai koefisien kelompok referensi adalah 0,639 diartikan apabila kelompok referensi berubah satu satuan, keputusan menggunakan jasa klinik kecantikan akan berubah 0,639 satuan dengan anggapan variabel lain tetap. Tanda positif pada koefisien regresi menunjukkan hubungan yang searah, artinya kenaikan kelompok referensi akan menyebabkan keputusan menggunakan jasa klinik kecantikan semakin tinggi.

Nilai koefisien regresi interaksi brand image dan kelompok referensi sebesar 0,042 artinya jika kelompok referensi berpengaruh positif pada hubungan brand image dengan keputusan menggunakan jasa klinik kecantikan. Makna tanda positif pada koefisien regresi adalah apabila skor pada variabel moderasi kelompok referensi meningkat sebanyak satu satuan, akan meningkatkan tingkat pengaruh brand image terhadap keputusan menggunakan jasa klinik kecantikan.

Berdasarkan tabel di atas juga dapat dilihat nilai t hitung variabel brand image sebesar 4,245 dengan signifikansi sebesar 0,000. Variabel kelompok referensi mempunyai nilai $\mathrm{t}$ hitung sebesar 12,063 dan signifikansinya adalah 0,000 dan variabel moderasi antara brand image dengan kelompok referensi dengan nilai t hitung 0,035 dengan signifikansi sebesar 0,508, disimpulkan variabel brand image dan kelompok referensi signifikan berpengaruh terhadap variabel keputusan menggunakan jasa klinik kecantikan. Namun kelompok referensi memiliki pengaruh yang lebih besar jika dibandingkan dengan brand image, hal ini 
Sanaji

dikarenakan kelompok referensi disini merupakan teman yang memiliki pengalaman atau telah merasakan langsung jasa dari klinik kecantikan, sehingga konsumen lebih mempertimbangkan sarannya bahkan menyesuaikan niat pembeliannya.

Sedangkan variabel moderasi brand image dengan kelompok referensi tidak signifikan atau dapat diartikan bahwa variabel kelompok referensi tidak dapat berinteraksi dengan brand image. Hal ini dikarenakan penggunaan jasa klinik kecantikan merupakan kebutuhan individu artinya masing-masing orang mempunyai kebutuhan yang berbeda, selain itu menggunakan jasa klinik kecantikan juga mempunyai resiko yang tinggi. Kelompok referensi bukan merupakan faktor yang memperkuat atau memperlemah hubungan brand image terhadap keputusan menggunakan jasa klinik kecantikan namun kelompok referensi merupakan faktor utama yang sarannya dipertimbangkan konsumen dalam keputusan menggunakan jasa klinik kecantikan.

Nilai Adjusted R Square dari model menunjukkan angka sebesar 0,452, yang artinya bahwa brand image $(\mathrm{X})$ dan interaksi antara brand image dengan kelompok referensi $(\mathrm{Z})$ mempengaruhi keputusan menggunakan jasa klinik kecantikan sebesar 0,452 (45,2\%). Sedangkan sisa sebesar 54,8\% atau 0,548 dijelaskan faktor lain yang tidak dijelaskan di penelitian ini.

\section{Simpulan}

Berdasarkan pembahasan hasil penelitian dapat disimpulkan terdapat pengaruh positif variabel brand image terhadap keputusan menggunakan jasa klinik kecantikan dan variabel kelompok referensi tidak dapat memoderasi hubungan brand image terhadap keputusan menggunakan jasa klinik kecantikan. Ketika konsumen mempunyai asosiasi terhadap merek klinik kecantikan meskipun tidak ada dorongan kelompok referensi maka keputusan menggunakan akan tetap tinggi, hal ini dikarenakan jasa kecantikan mempunyai resiko penggunaan tinggi sehingga saran dari kelompok referensi bukan hanya memperkuat namun merupakan faktor utama yang dipertimbangkan konsumen sebelum memutusan menggunakan jasa klinik kecantikan.

Dari simpulan di atas sehingga dapat disarankan beberapa hal yaitu, khusus penelitian pada jasa klinik kecantikan untuk mengkombinasikan variabel bebas dalam penelitian ini atau meneliti secara terpisah variabel bebas yang tidak dilakukan dalam penelitian ini, karena mengingat masih terdapat pengaruh $54,8 \%$ dari variabel lainnya, seperti harga dan kualitas layanan. Variabel kelompok referensi tidak dapat memoderasi hubungan antara brand image dengan keputusan menggunakan jasa klinik kecantikan namun hanya berfungsi sebagai variabel independen (variabel predictor) dalam jasa klinik kecantikan, dan disarankan menggunakan variabel kelompok referensi sebagai variable independen (predictor) di jasa klinik kecantikan. Sebaiknya untuk peneliti selanjutnya menggunakan jurnal yang sesuai dengan objek yang diteliti yaitu tentang jasa klinik kecantikan. Disarankan untuk melihat pada jurnal kesehatan untuk lebih mempermudah pemahaman.

\section{Daftar Pustaka}

Akbarini, Yoga Famei. 2017. Pengaruh Kelompok Referensi, diferensiasi Produk dan Harga Terhadap Keputusan Pembelian Produk Perawatan (Studi Pada Konsumen Larissa Aesthetic Center Cabang Ponorogo). Jurnal Ilmu Manajemen. Vol. 5 No. 1. Hal 1-8.

Erha Clinic. 2017. Profil Erha Clinic. (www.erha.co.id) Diakses pada tanggal 02 Maret 2017. 
Sanaji

Escalas, Jennifer Edson dan James R. Bettman. 2003. You Are What They Eat : The Influence of Reference Groups on Consumer's Connections to Brands. Journal of Consumer Psychology. Vol. 13 No 3. Hal 339 - 348.

Ferrinadewi, Erna. 2008. Merek dan Psikologi Konsumen Implikasi pada Strategi Pemasaran. Yogyakarta : Penerbit Graha Ilmu.

Ghozali, Imam. 2013. Aplikasi Analisis Multivariete dengan Program IBM SPSS 23. Semarang : Badan Penerbit Universitas Diponegoro.

Hoonsopon, Danupol dan Wilert Puwirat. 2016. The Effect of Reference Groups on Purchase Intentions : Evidence in Distinct Types of Shoppers and Product Involvement. Australasian Marketing Journal. Vol. 05 No. 001. Hal 1-8.

Keller, Kevin Lane. 2013. Strategic Brand Management Building, Measuring, and Managing Brand Equity. Fourth Edition. England : Pearson.

Kim, Miyoung dan Hailin Qu. 2016. The Moderating Effects of Three Reference Groups on Asian Pleasure Travelers Destination Value. Journal of Travel \& Tourism Marketing. ISSN : 1054-8408.

Kitapchi, Olgun, dkk. 2014. The Impact Service Quality Dimensions on Patient Satisfaction, Repurchase Intentions and Word-of-Mouth Communication in the Public Healthcare Industry. Social and Behavioral Sciences. 148 (2014) hal 161-169.

Klinik LBC. 2017. Profil Klinik LBC. (www.kliniklbc.com) Diakses pada tanggal 02 Maret 2017.

Kotler, Philip dan Kevin Lane Keller. 2009. Manajemen Pemasaran. Jilid 1. Edisi Ketiga Belas. Terjemahan Bob Sabran, MM. Jakarta : Penerbit Erlangga.

Kusdyah, Ike. 2012. Persepsi Harga, Persepsi Merek, Persepsi Nilai dan Keinginan Pembelian Ulang Jasa Clinic Kesehatan (Studi Kasus Erha Clinic Surabaya). Jurnal Manajemen Pemasaran. Vol. 7 No. 1. ISSN 1970-235X. Hal 25-32.

Lin, Nan-Hong dan Bih-Shya Lin. 2007. The Effect of Brand Image and Product Knowledge on Purchase Intention Moderated by Price Discount. Journal of Internasional Management Studies. Hal 121 - 132.

Lupiyoadi, Rambat. 2014. Manajemen Pemasaran Jasa. Edisi Ketiga. Jakarta : Salemba Empat.

Mahmudah, Indah Siti dan Monika Tiarawati. 2013. Pengaruh Kualitas Produk, Citra Merek, dan Harga Terhadap Keputusan Pembelian Pond's Flawless White. Jurnal Ilmu Manajemen. Vol. 1 No. 3. Hal 837 - 847.

Marketingcoid. 2016. Service Quality Index 2016. (www.marketing.co.id/service-qualityaward-2016) Diakses pada 13 Maret 2017.

Miracle Aesthetic Clinic. 2017. Klinik Kecantikan terdepan di Indonesia. (www.miracleclinic.com) Diakses pada tanggal 02 Maret 2017.

Natasha Skin Clinic Center. 2017. Klinik Kecantikan Pusat Perawatan Wajah dan Kulit. (www.natasha-skin.com) Diakses pada 02 Maret 2017.

Nitisusastro, Mulyadi, 2012. Perilaku Konsumen dalam Perspekstif Kewirausahaan. Bandung : Penerbit Alfabeta. 
Sanaji

Pawar, Sangeeta N. 2013. Evaluation of Youth Appeal For Valuation of Beauty Care Products with Reference to Mumbai Market. Scholarly Research Journal for Humanity Science \& English Language. Hal 1031-1040.

Peter, J. Paul dan Jerry C. Olson. 2014. Perilaku Konsumen \& Strategi Pemasaran. Edisi 9. Buku 2. Jakarta : Salemba Empat.

Pramudi, Riski Yuliana. 2015. Pengaruh Gaya Hidup Konsumtif dan Kelompok Referensi Terhadap Keputusan Pembelian Kosmetik Lokal. Jurnal Riset Ekonomi dan Manajemen. Vol. 15. No. 2. Hal 280-301.

Schiffman, Leon dan Leslie Lazar Kanuk. 2008. Perilaku Konsumen. Edisi Ketujuh. Jakarta : PT Indeks.

Shahbazi, dkk. 2013. Identifying the Decision Criterion for Choosing Beauty Parlor and Salon : A Marketing Communication Perspective. International Journal of Business and Management Invention. Vol. 2 Issue 10. Hal. 18-26.

Sumarwan, Ujang. 2011. Perilaku Konsumen. Edisi Kedua. Bogor : Penerbit Ghalia Indonesia.

Suryani, Titik. 2012. Perilaku Konsumen Implikasi pada Strategi Pemasaran. Edisi Pertama. Yogyakarta : Graha Ilmu.

Tjiptono, Fandy dan Chandra Gregorius. 2012. Pemasaran Strategik. Edisi Kedua. Yogyakarta : Penerbit Andi.

Tjiptono, Fandy. 2011. Manajemen \& Strategi Merek. Yogyakarta : Penerbit Andi.

Top Brand Award. 2017. Top Brand Index (www.topbrand-award.com). Diakses pada tanggal 17 Juli 2017. 